\title{
Antioxidant and Angiotensin-Converting Enzyme Inhibitory Activity of Eucalyptus camaldulensis and Litsea glaucescens Infusions Fermented with Kombucha Consortium
}

\author{
Claudia I. Gamboa-Gómez ${ }^{1}$, Rubén F. González-Laredo ${ }^{1}$, José Alberto Gallegos-Infante ${ }^{1}$, \\ $M^{a}$ del Mar Larrosa Pérez ${ }^{2}$, Martha R. Moreno-Jiménez ${ }^{1}$, Ana G. Flores-Rueda and \\ Nuria E. Rocha-Guzmán ${ }^{1 *}$ \\ ${ }^{1}$ Durango Institute of Technology, Felipe Pescador 1830 Ote., MX-34080 Durango, Durango, Mexico \\ ${ }^{2}$ European University of Madrid, Calle Tajo, s/n, Villaviciosa de Odón, ES-28670 Madrid, Spain
}

Received: January 26, 2016

Accepted: May 11, 2016

\begin{abstract}
Summary
Physicochemical properties, consumer acceptance, antioxidant and angiotensin-converting enzyme (ACE) inhibitory activities of infusions and fermented beverages of Eucalyptus camaldulensis and Litsea glaucescens were compared. Among physicochemical parameters, only the $\mathrm{pH}$ of fermented beverages decreased compared with the unfermented infusions. No relevant changes were reported in consumer preference between infusions and fermented beverages. Phenolic profile measured by UPLC MS/MS analysis demonstrated significant concentration changes of these compounds in plant infusions and fermented beverages. Fermentation induced a decrease in the concentration required to stabilize $50 \%$ of DPPH radical (i.e. lower $\mathrm{IC}_{50}$ ). Additionally, it enhanced the antioxidant activity measured by the nitric oxide scavenging assay ( $14 \%$ of E. camaldulensis and $49 \%$ of L. glaucescens); whereas relevant improvements in the fermented beverage were not observed in the lipid oxidation assay compared with unfermented infusions. The same behaviour was observed in the inhibitory activity of ACE; however, both infusions and fermented beverages had lower $\mathrm{IC}_{50}$ than positive control (captopril). The present study demonstrated that fermentation has an influence on the concentration of phenolics and their potential bioactivity. E. camaldulensis and L. glaucescens can be considered as natural sources of biocompounds with antihypertensive potential used either as infusions or fermented beverages.
\end{abstract}

Key words: herbal infusions, fermented beverages, kombucha, antioxidant activity, polyphenols

\section{Introduction}

In recent years, the consumption of herbal infusions around the world has increased due to their beneficial health effects. These beverages are prepared by placing a small amount of the selected plant material in freshly boiled water, allowing the preparation to steep for a short period of time (1). Although herbal infusions do not have any particular nutritional value, they represent an impor- tant source of bioactive compounds such as polyphenols. It has been shown that these compounds can act by diverse mechanisms providing significant protection against chronic diseases (2). For example, the consumption of some herbal polyphenols with antioxidant activity may regulate hypertension through inhibition of the angiotensin-converting enzyme (ACE), a key component in the renin-angiotensin aldosterone system which regulates blood pressure (3). 
Recently, several research studies have focused on enhancing the beneficial health potential of herbal infusions. For example, Aloulou et al. (4) reported that fermentation process with kombucha enhanced the phenolic content, antioxidant activity and $\alpha$-amylase inhibitory activity in five commonly consumed teas. Similar results were observed by Velićanski et al. (5) in fermented lemon balm (Melissa officinalis L.) infusion; they reported an enhancement of phenolic compounds such as rosmarinic, caffeic and ferulic acids (1.3-, 1.9- and 4.6-fold higher, respectively), as well as major antioxidant activity against DPPH radicals than in unfermented infusions.

The beneficial effects of these fermented beverages are attributed to the presence of restructured polyphenols, gluconic acid, glucuronic acid, lactic acid, vitamins, amino acids, antibiotics and a variety of micronutrients produced during fermentation (6).

The fermentation process involves the activity of yeasts that ferment glucose and fructose to ethanol, which is then oxidized to acetic acid by acetic acid bacteria (AAB). The main source of carbon in this process is sucrose. The sugar is hydrolyzed by the enzyme invertase from the yeast present in the kombucha consortium, producing ethanol via the metabolic pathway of glycolysis, with a preference for fructose as the substrate. Subsequently, $\mathrm{AAB}$ convert glucose and ethanol into gluconic and acetic acids (7).

In occidental countries, the consumption of tea prepared from Camellia sinensis and analogues, such as fermented beverages, is not that common; on the contrary, the consumption of infusions made with plant materials typical of each region predominates. In this same regard, in a previous study we analyzed phenolic composition and anti-inflammatory effect of different herbal infusions (8), including Eucalyptus camaldulensis and Litsea glaucescens. Results showed anti-inflammatory activity through the positive modulation of COX-2, TNF $\alpha, N F \kappa B$, and IL-8 in HT-29 cells, especially of L. glaucescens. Even though both plants have different traditional uses (e.g. Eucalyptus camaldulensis is consumed for decongestant, antiseptic, anti-inflammatory or antibiotic, among other purposes, whereas Litsea glaucescens infusion is traditionally consumed for its bactericidal, antiseptic, expectorant and anti-inflammatory properties), both of them contain bioactive compounds with antioxidant activity such as polyphenols $(8,9)$.

Although these plant materials are commonly consumed as infusions, the fermentation process may or may not enhance their positive effects. This is unknown and can be poorly related with black tea, despite the fact that fermentation conditions are similar. Therefore, the aim of this work is to compare chemical composition, consumer acceptance, antioxidant and angiotensin-converting enzyme inhibitory activities of E. camaldulensis and L. glaucescens in traditional infusions and fermented beverages prepared with the kombucha consortium.

\section{Materials and Methods}

\section{Plant materials}

Representative samples of Eucalyptus camaldulensis and Litsea glaucescens were collected in Ciudad de Duran- go, Durango, Mexico, and positively identified by botanist Socorro González-Elizondo. Voucher specimens (nos. 44008 and 44007, respectively) were deposited at the Herbarium of the Interdisciplinary Research Centre for Comprehensive Regional Development, Durango Unit (CIIDIR-IPN, Durango, Mexico).

\section{Preparation of herbal infusions and fermented beverages}

Both materials were dried at room temperature in shade, ground $(1.13 \mathrm{~mm})$ and stored in the dark for later determinations. Infusions ( $1 \%$, by mass per volume) were prepared by adding $200 \mathrm{~mL}$ of freshly boiled water to $2 \mathrm{~g}$ of dried ground sample. Infusions were left to stand for $10 \mathrm{~min}$ and filtered.

Fermentation was performed using kombucha culture from a Mexican trading house (Healthy, Natural Life, Tlaquepaque, Jalisco, Mexico). A previous study reported that kombucha consortium contained yeast strains such as: Saccharomyces cerevisiae, Saccharomyces bisporus, Saccharomycodes ludwigii, Torulopsis sp., Zygosaccharomyces sp., Dekkera, Kazachstania and Pichia, among others. Bacteria such as Acetobacter, Gluconacetobacter, Lactobacillus, Lactococcus, Leuconostoc, Bifidobacterium, Thermus, Allobaculum, Ruminococcaceae incertae sedis and Propionibacterium, among others, have also been reported (10).

The fermentation of infusions was performed using the conditions reported by Vázquez-Cabral et al. (7). The infusions were cooled at room temperature, and then sweetened by dissolving $10 \mathrm{~g} / \mathrm{L}$ of sucrose. In small bioreactors, $1 \mathrm{~L}$ of sweetened infusions was inoculated and acidified with $2.5 \mathrm{~g}$ of inoculum (biofilm with a symbiotic culture of bacteria and yeasts) and $100 \mathrm{~mL}$ of black tea vinegar, respectively. The bioreactors were covered with cheesecloth, and the fermentation at $(25 \pm 1){ }^{\circ} \mathrm{C}$ was monitored for seven days. On the last fermentation day, the biomass was removed from the beverage by filtration.

For preparation of black tea vinegar, inoculum was grown at $25^{\circ} \mathrm{C}$ in sweetened (sucrose, $10 \%$ ) black tea for 20 days. Freshly cultured kombucha was used for further subcultures or for fresh fermentation batches.

\section{Physicochemical evaluation}

The $\mathrm{pH}$ was measured using a digital $\mathrm{pH}$ meter $(\mathrm{pH}$ meter sension ${ }^{\mathrm{TM}} 1$; Hach, Loveland, CO, USA) calibrated at $\mathrm{pH}=4,7$ and 10 at $25{ }^{\circ} \mathrm{C}$. Colour characteristics of infusions were evaluated by measuring their colour coordinates with a colourimeter (chroma meter CR-400/410; Konica Minolta, Osaka, Japan). Colour intensity measurements were expressed as $L^{*}$ (lightness), $a^{*}$ (red/green colour), and $b^{*}$ (yellow/blue colour) values.

\section{Consumer preference tests}

The consumer preference evaluation of both, infusions and fermented beverages was performed by 15 untrained panellists who declared drinking a cup of any herbal infusion at least once a week. The panellists ranked the samples according to the following scale: 1=very unpleasant to $9=$ very pleasant. The samples were coded with random three digit numbers. Black tea was used as a positive control. 


\section{Sugar content in fermented beverages}

Sample analysis was carried out with an Acquity ultra-performance liquid chromatography (UPLC) system (Waters Corp., Milford, MA, USA) coupled with an evaporative light scattering detector (ELSD; Waters Corp., Wexford, Ireland). The LC system consisted of a sample manager $\left(5^{\circ} \mathrm{C}\right)$ and a binary solvent manager. The column used to determine fructose, glucose and sucrose was an Acquity UPLC BEH Amide, $100 \mathrm{~mm} \times 2.1 \mathrm{~mm}, 1.7 \mu \mathrm{m}$ (Waters Corp., Wexford), operated at $50{ }^{\circ} \mathrm{C}$. The elution profile used two solvents (both J.T.Baker, Mexico City, Mexico): acetonitrile/water (80:20) with $0.1 \% \mathrm{NH}_{4} \mathrm{OH}$ (solvent A), and acetonitrile/water (30:70) with $0.1 \%$ $\mathrm{NH}_{4} \mathrm{OH}$ (solvent B) and an initial gradient of $5-60 \%$ B in $5 \mathrm{~min}$, isocratic by $1 \mathrm{~min}$, reset and equilibrated for 5.5 $\mathrm{min}$. The flow rate was $0.25 \mathrm{~mL} / \mathrm{min}$. The UPLC control and data processing were performed using the Masslinx (Waters Corp., Milford) software.

\section{Ultra-performance liquid chromatography coupled with tandem mass spectrometry analysis}

Sample analysis was carried out with an Acquity UPLC system (Waters Corp., Milford) coupled with a tandem Xevo TQ-S triple quadrupole mass spectrometer (Waters Corp., Wexford). The LC system consisted of a sample manager $\left(20^{\circ} \mathrm{C}\right)$ and a binary solvent manager. The column used to determine flavan-3-ols was an Acquity UPLC BEH C18, $50 \mathrm{~mm} \times 2.1 \mathrm{~mm}, 1.7 \mu \mathrm{m}$ (Waters Corp., Wexford) operated at $40^{\circ} \mathrm{C}$. The elution profile included two solvents (both J.T.Baker): acidified water with $1 \%$ formic acid (solvent A) and methanol LC-MS grade (solvent B): initial $98 \%$ A, 0-2 min, $68 \%$ A, 2-3.8 min, $55 \%$ A, 3.8-4.5 min, $45 \%$ A, 4.5-6.0 min, 5 \% B (linear gradient) for column washing and subsequently $6.0-9.5 \mathrm{~min}, 98 \%$ A for column stabilization. Multiple reaction monitoring (MRM) data were collected from 0 to $9.5 \mathrm{~min}$. Negative ionization mode was used for MS assays. Electron spray ionization (ESI) conditions were as follows: capillary voltage $2.85 \mathrm{kV}$, desolvation temperature $500{ }^{\circ} \mathrm{C}$, source temperature $150{ }^{\circ} \mathrm{C}$, desolvation and cone gas 794 and 151 $\mathrm{L} / \mathrm{h}$, respectively, and collision gas $0.14 \mathrm{~mL} / \mathrm{min}$. For identification and quantification, a multiple reaction monitoring mode with standards was used. Rutin $(20 \mathrm{ng} / \mu \mathrm{L})$ was employed to check the stability of the ionization efficiency of mass spectrometer and a mixture of phenolic compound standards ( $20 \mathrm{ng} / \mu \mathrm{L}$; Sigma Corp., St. Louis, MO, USA) for monitoring retention time and $\mathrm{m} / \mathrm{z}$ values. The UPLC and tandem Xevo TQ-S triple quadrupole mass spectrometer control and data were processed using MassLinx v. 4.1 (Waters Corp., Milford) software.

\section{Radical scavenging and chain-breaking assay}

Antioxidant capacity of herbal infusions and fermented beverages was evaluated using the stable radical 2,2-diphenyl-1-picrylhydrazyl (DPPH'; Sigma Corp.) method described by Brand-Williams et al. (11). The percentage of scavenging or quenching radicals, $Q$, was calculated using the following equation:

$$
Q=\left(\frac{A_{0}-A_{c}}{A_{0}}\right) \cdot 100
$$

where $A_{0}$ is the absorbance of the blank, and $A_{\mathrm{c}}$ is the absorbance of the mixture of radical and sample at different concentrations. For the calculation of the half maximal inhibitory concentration $\left(\mathrm{IC}_{50}\right.$, in $\left.\mu \mathrm{g} / \mu \mathrm{L}\right)$, the logarithm of the concentration against the inhibition percentage was plotted.

For chain-breaking kinetics, $3 \mathrm{~mL}$ of $3 \cdot 10^{-5} \mathrm{~mol} / \mathrm{L}$ of DPPH in methanol solution was used. The reaction began with the addition of $10 \mu \mathrm{L}$ of herbal infusion or fermented beverage at previously determined $\mathrm{IC}_{50}$ ( $\mu \mathrm{g}$ of total content of analyzed flavonoids per $\mu \mathrm{L}$ ). The DPPH bleaching was monitored spectrophotometrically at $515 \mathrm{~nm}$ with a spectrophotometer (model 50-BIO; Varian Cary ${ }^{\circledR}$, Melbourne, Australia) at $25{ }^{\circ} \mathrm{C}$ for at least $60 \mathrm{~min}$ (12). The following equation was used to obtain the reaction rate, $k$ :

$$
\frac{1}{A^{3}}-\frac{1}{A_{0}^{3}}=-3 k t
$$

where $A$ is the absorbance at increasing time $(t)$, and $A_{0}$ is the initial absorbance. Results on dry mass basis were expressed as both $\mathrm{IC}_{50}$ and chain-breaking activity $(k / \mathrm{mg})$. Catechin was used as positive control.

\section{Lipid peroxidation assay}

Lipid peroxidation was determined according to Jozwik et al. (13) with several modifications. Inhibition of the formation of thiobarbituric acid reactive substances (TBARS), a lipid oxidation product, was quantified with a spectrophotometer (model 50-BIO; Varian Cary ${ }^{\circledR}$ ), using healthy human plasma donated by the blood bank of the Public General Hospital (City of Durango, Durango, Mexico). Inhibition of plasma oxidation was evaluated using Fenton's reagent with the addition of phosphate buffer ( $150 \mu \mathrm{L}$ of $500 \mathrm{mM} \mathrm{H}_{2} \mathrm{O}_{2}$ and $150 \mu \mathrm{L}$ of $100 \mathrm{mM} \mathrm{FeCl}_{3}$ for 3 $\mathrm{h}$ at $37^{\circ} \mathrm{C}$; Caledon Laboratories Ltd, Georgetown, ON, Canada). Catalyzed plasma (600 $\mu \mathrm{L})$ oxidation was evaluated for each herbal infusion and fermented beverage samples $(100 \mu \mathrm{L})$ at several concentrations using phosphate buffer $(\mathrm{pH}=7.4)$ to reach the final volume $(1 \mathrm{~mL})$. Prior to oxidation phase, a thiobarbituric acid (TBA) reagent (MP Biomedicals, LCC, Illkirch, France) was prepared consisting of $40.5 \mathrm{~mL}$ of $20 \%$ acetic acid buffered at $\mathrm{pH}=3.5$ with $1 \mathrm{M} \mathrm{NaOH}, 13.2 \mathrm{~mL}$ of $8.2 \%$ SDS (Sigma Corp.), $40.5 \mathrm{~mL}$ of $0.8 \%$ TBA, and made up to $100 \mathrm{~mL}$ with double distilled water. Samples $(1 \mathrm{~mL})$ were mixed with $4.0 \mathrm{~mL}$ of TBA reagent, incubated at $96{ }^{\circ} \mathrm{C}$ for $80 \mathrm{~min}$, and cooled down on ice. Then, they were mixed with $n$-butanol ( 5 $\mathrm{mL}$ ) and centrifuged at $3000 \times g$ for $15 \mathrm{~min}$. The ability of the samples to inhibit plasma oxidation was determined by the absorbance decrease at $532 \mathrm{~nm}$. For the calculation of the $\mathrm{IC}_{50}(\mu \mathrm{g} / \mu \mathrm{L})$, the logarithm of the concentration against the inhibition percentage was plotted. Catechin standard (Sigma Corp.) was included as positive control.

\section{Nitric oxide scavenging assay}

Infusions and fermented beverages were screened for antioxidant capacity potential using the nitric oxide scavenging assay described by Balakrishnan et al. (14). The absorbance of the chromophores formed during the diazotization of nitrite with sulphanilamide, subsequently coupled with naphthylethylenediamine dichloride (Griess reagent, Sigma Corp.) was read at $546 \mathrm{~nm}$ (spectrophotome- 
ter model 50-BIO; Varian Cary $\left.^{\circledR}\right)$. Catechin was used as a positive control and results were expressed as $\mathrm{IC}_{50}$.

\section{Angiotensin-converting enzyme inhibitory activity}

The angiotensin-converting enzyme (ACE) inhibitory activity of infusions and fermented beverages was screened using the methodology described by Actis-Goretta et al. (15). The activity of ACE from rabbit lung $(0.05 \mathrm{U} / \mathrm{mg}$ of protein; Sigma Corp.) was evaluated following the hydrolysis of hippuryl-L-histidyl-L-leucine to hippuric acid. The formed hippuric acid was separated and quantified with Waters HPLC system consisting of Waters 717 plus autosampler and Waters 600 pump (Waters Corp., Milford). Chromatographic separations were performed with a Supelcosil LC-18-DB column, $150 \mathrm{~mm} \times 4.6 \mathrm{~mm}, 5 \mu \mathrm{m}$ i.d. (Waters Corp., Wexford), and a mobile phase composed of $0.1 \%$ (by volume) trifluoroacetic acid in a volume ratio of $\mathrm{H}_{2} \mathrm{O}$ and acetonitrile of 75:25 (J.T.Baker). The flow rate used to achieve a retention time of $2.9 \mathrm{~min}$ was $1 \mathrm{~mL} / \mathrm{min}$. The hippuric acid detection was carried out at $228 \mathrm{~nm}$ (Waters 2487 UV spectrophotometric detector; Waters Corp., Milford). Commercial hippuric acid was used as the standard (Sigma Corp.). For the inhibition of ACE activity by infusions and fermented beverages, a mixture of $10 \mu \mathrm{L}$ of ACE $(0.05 \mathrm{U} / \mathrm{mg}$ of protein) in $50 \mathrm{mM} \mathrm{HCl}$-Tris, $300 \mathrm{mM} \mathrm{NaCl}(\mathrm{pH}=8.3)$, and different concentrations of samples to reach the volume of $90 \mu \mathrm{L}$ was pre-incubated for $5 \mathrm{~min}$ at $37^{\circ} \mathrm{C}$. A volume of $10 \mu \mathrm{L}$ of $3 \mathrm{mM}$ hippuryl-L-histidyl-L-leucine (1 mM final concentration; Sigma Corp.) was added to the above mixture and incubated for $30 \mathrm{~min}$ at $37^{\circ} \mathrm{C}$. The reaction was stopped by placing the sample in a water bath at $100{ }^{\circ} \mathrm{C}$ for $5 \mathrm{~min}$. For the calculation of the $\mathrm{IC}_{50}(\mu \mathrm{g} / \mu \mathrm{L})$ the logarithm of the concentration against the inhibition activity percentage was plotted. Captopril (Sigma Corp.) was used as a positive control.

\section{Statistical analysis}

Data were expressed as mean value \pm standard error (SE). Statistical significance was determined by one-way variance analysis (ANOVA) $(p<0.05)$ followed by the Tukey's test, where $\mathrm{p}<0.05$ was considered significant. Statistical analysis was made using JMP v. 5.0.1 software (SAS Institute, Cary, NC, USA).

\section{Results and Discussion}

Results of physicochemical characterization are shown in Table 1. It was observed that the $\mathrm{pH}$ of fermented beverages decreased by 2 units compared with the unfermented infusions. The overall decrease in $\mathrm{pH}$ is attributable to the increased concentration of organic acids produced during fermentation by bacteria and yeasts from the tea fungus. In concordance, Velićanski et al. (16) reported decreased values of $\mathrm{pH}$ (between 2 and 3 units) in analogues of kombucha at the same fermentation times.

On the other hand, several authors reported changes in colour as a consequence of fermentation. For example, a progressive lightening of colour in fermented teas has been reported $(17,18)$. However, in this work we did not observe significant differences between infusions and fermented beverages (Table 1). This could be attributed to the nature of plant materials and their chemical composition. Contrary to the species studied in this work, epigallocatechin-3-gallate (ECGC) is the main polyphenol found in green tea (about $59 \%$ of total catechins) (19). In fermentation EGCG is the major precursor for other compounds such as theaflavins $(20,21)$. These and other compounds, including bisflavanols and thearubigins are mainly responsible for the colour change in kombucha beverages (22).

During fermentation, the sucrose is hydrolyzed to glucose and fructose by yeast. Glucose is mainly converted into gluconic acid via the pentose phosphate pathway by acetic acid bacteria, whereas fructose is metabolized to acetic acid, and in minor proportion to gluconic acid (23). The results of sucrose consumption can be observed in Table 1. In both fermented beverages, the kombucha consortium utilized more than $70 \%$ of sucrose for fermentation process. This is consistent with the results of residual glucose and fructose (Table 1), suggesting an active process of fermentation in these herbal infusions (Table 1).

Plant infusions such as E. camaldulensis are traditionally consumed due to their pleasant smell and taste; however, the changes that occur during fermentation process can alter the consumer preference despite their nutraceutical potential. For this reason, we compared the acceptability of infusions and fermented beverages. For this eval-

Table 1. Physicochemical evaluation and consumer acceptance of herbal infusions and fermented beverages of Litsea glaucescens and Eucalyptus camaldulensis

\begin{tabular}{|c|c|c|c|c|}
\hline \multirow{2}{*}{ Parameter } & \multicolumn{2}{|c|}{ Litsea glaucescens } & \multicolumn{2}{|c|}{ Eucalyptus camaldulensis } \\
\hline & Infusion & Fermented beverage & Infusion & Fermented beverage \\
\hline $\mathrm{pH}$ & $(5.10 \pm 0.05)^{\mathrm{a}}$ & $(3.00 \pm 0.01)^{\mathrm{b}}$ & $(5.00 \pm 0.05)^{\mathrm{a}}$ & $(3.00 \pm 0.05)^{b}$ \\
\hline$L^{*}$ & $(22.00 \pm 0.05)^{\mathrm{a}}$ & $(22.10 \pm 0.01)^{\mathrm{a}}$ & $(22.00 \pm 0.05)^{\mathrm{a}}$ & $(22.10 \pm 0.02)^{\mathrm{a}}$ \\
\hline$a^{*}$ & $(-0.13 \pm 0.01)^{\mathrm{a}}$ & $(-0.14 \pm 0.02)^{\mathrm{a}}$ & $(-0.14 \pm 0.05)^{\mathrm{a}}$ & $(-0.14 \pm 0.01)^{\mathrm{a}}$ \\
\hline$b^{*}$ & $(0.30 \pm 0.01)^{\mathrm{a}}$ & $(0.40 \pm 0.07)^{\mathrm{a}}$ & $(0.30 \pm 0.01)^{\mathrm{a}}$ & $(0.33 \pm 0.02)^{a}$ \\
\hline$w($ consumed sucrose $) / \%$ & N.D. & $(70.40 \pm 0.06)^{\mathrm{a}}$ & N.D. & $(75.6 \pm 0.3)^{\mathrm{a}}$ \\
\hline$\gamma($ residual fructose $) /(\mathrm{mg} / \mathrm{mL})$ & N.D. & $(37.50 \pm 0.02)^{\mathrm{a}}$ & N.D. & $(37.20 \pm 0.02)^{\mathrm{a}}$ \\
\hline$\gamma($ residual glucose $) /(\mathrm{mg} / \mathrm{mL})$ & N.D. & $(43.9 \pm 0.2)^{\mathrm{a}}$ & N.D. & $(40.1 \pm 0.3)^{\mathrm{a}}$ \\
\hline Consumer preference (hedonic scale) & $(4.0 \pm 0.4)^{\mathrm{a}}$ & $(4.0 \pm 0.4)^{\mathrm{a}}$ & $(4.0 \pm 0.6)^{\mathrm{a}}$ & $(3.0 \pm 0.2)^{b}$ \\
\hline
\end{tabular}

Values are means of duplicate determinations \pm standard error. Different letters in each row indicate statistical difference ( $\mathrm{p} \leq 0.05)$ by Tukey's test. N.D.=not determined 
uation black tea infusion and fermented beverage were included as positive controls, resulting in 5 and 4 score points on a hedonic scale for consumer preference, respectively. Results for E. camaldulensis and L. glaucescens infusions and fermented beverages are shown in Table 1. Both herbal infusions have similar consumer preferences, but 1 point lower than the black tea infusion. Among fermented beverages, E. camaldulensis had lower acceptability, whereas L. glaucescens had similar results to the control. It has been reported that biotransformation of several compounds produced during fermentation increases the preference by consumers compared with certain herbal infusions (7). Nevertheless, our results have not shown any differences in the acceptability between herbal infusions and fermented beverages; even when a minor decrease ( 1 point on hedonic scale) for fermented E. camaldulensis beverage was observed. This could be attributed to the formation of other compounds that can influence flavour; however, more chemical studies are needed.

\section{Phenolic profile and concentrations of herbal infusions and fermented beverages}

Results of phenolic profile of infusions and fermented beverages are shown in Fig. 1. Compounds such as gallocatechin, epigallocatechin, gallocatechin gallate, catechin, rutin, kaempferol and quercetin were identified in both beverages. The most abundant detected compound was gallocatechin gallate (GCG), being higher in L. glaucescens infusions and in fermented E. camaldulensis beverage.
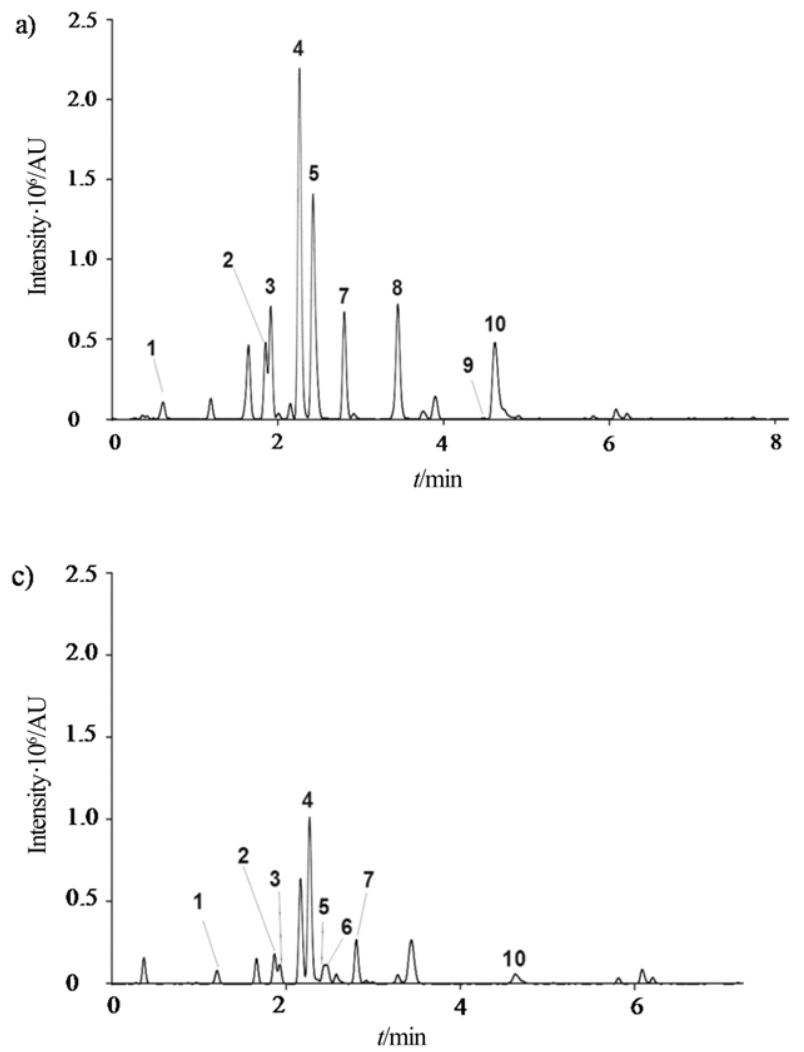

Chromatogram results (Fig. 1) and concentrations (Table 2) of each identified compound demonstrated that the fermentation influenced the polyphenols present in the herbal infusions of each plant differently. For instance, in fermented L. glaucescens beverage, the concentration of GCG decreased significantly ( $\mathrm{p}<0.05 ; 1.8$-fold), whereas in fermented $E$. camaldulensis beverage, the concentration increased (1.8-fold), both compared with their unfermented infusions. A similar trend was observed by Jayabalan et al. $(18,24)$, who reported an increased concentration of total phenolics of kombucha beverages after the fermentation. This could be attributed to the degradation of polyphenol complexes, as a consequence of the increased acidity during fermentation and to the enzymes produced by the kombucha consortium (25).

On the other hand, the decreased concentration of phenolic compounds observed in fermented L. glaucescens beverage could be explained by the partial oxidation of polyphenols to form polymerized compounds with higher molecular mass (16), and thus lower concentration of these compounds.

\section{Antioxidant capacity of beverages}

Results of DPPH radical scavenging activity showed that both herbal infusions had antioxidant activity, especially that of E. camaldulensis, with its $\mathrm{IC}_{50}$ closer to the positive control (Table 3). Despite the chain-breaking DPPH activity results, the fermentation process induced a decrease in the concentration required to stabilize $50 \%$ of
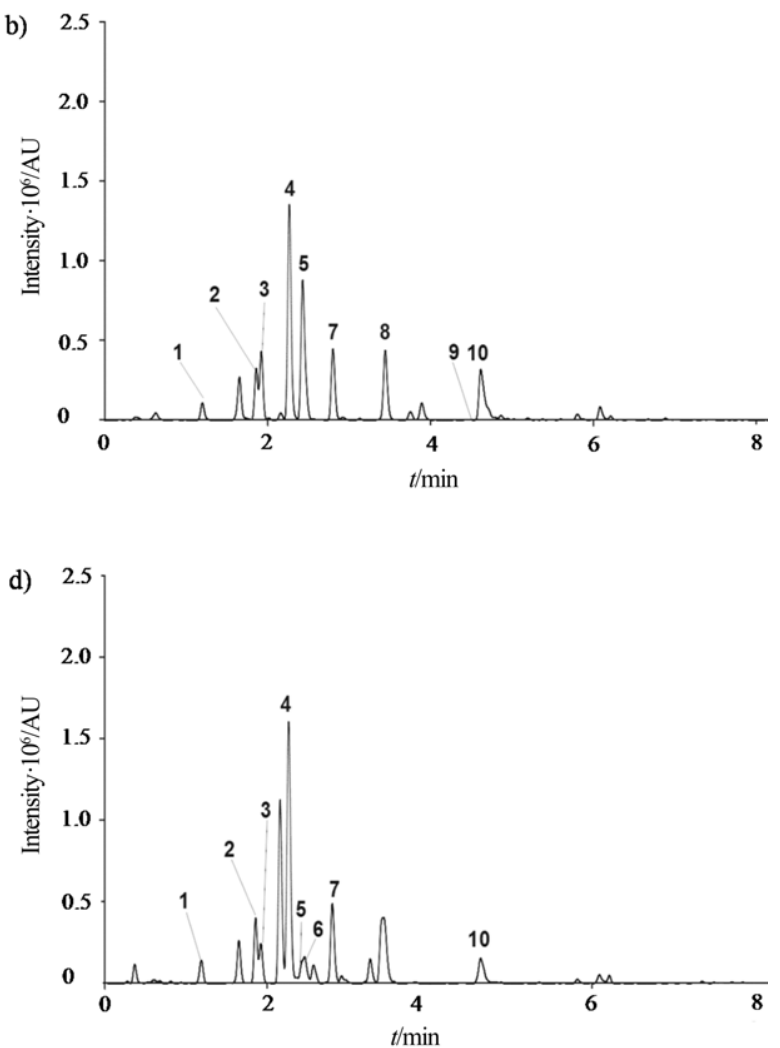

Fig. 1. LC-ESI-MS/MS profile of: a) Litsea glaucescens infusion, b) fermented Litsea glaucescens beverage, c) Eucalyptus camaldulensis infusion, and d) fermented Eucalyptus camaldulensis beverage. Identified compounds by retention time and MS/MS: 1=gallocatechin, $2=$ epigallocatechin, $3=$ catechin, $4=$ gallocatechin gallate, $5=$ epicatechin, $6=$ epigallocatechin gallate, $7=$ epicatechin gallate, $8=$ rutin, $9=$ kaempferol and $10=$ quercetin 
Table 2. Ultra-performance liquid chromatography (UPLC) coupled with tandem mass spectrometry (MS/MS). MS data and concentration of major phenolic compounds found in infusion and fermented products

\begin{tabular}{|c|c|c|c|c|c|c|c|}
\hline \multirow{3}{*}{ Compound } & \multirow{3}{*}{$\frac{t_{\mathrm{R}}}{\min }$} & \multirow{3}{*}{$\frac{[\mathrm{M}-\mathrm{H}]^{-}}{m / z}$} & \multirow{3}{*}{ MS/MS ions } & \multicolumn{4}{|c|}{$\gamma /(\mu \mathrm{g} / \mathrm{mL})$} \\
\hline & & & & \multicolumn{2}{|c|}{ Litsea glaucescens } & \multicolumn{2}{|c|}{ Eucalyptus camaldulensis } \\
\hline & & & & Infusion & $\begin{array}{c}\text { Fermented } \\
\text { beverage }\end{array}$ & Infusion & $\begin{array}{c}\text { Fermented } \\
\text { beverage }\end{array}$ \\
\hline Gallocatechin & 1.19 & 305 & 164,125 & $2.2 \pm 0.2$ & $1.78 \pm 0.09$ & $1.41 \pm 0.08$ & $2.6 \pm 0.3$ \\
\hline Epigallocatechin & 1.85 & 305 & 164,125 & $6.4 \pm 0.3$ & $4.58 \pm 0.03$ & $2.66 \pm 0.07$ & $5.57 \pm 0.09$ \\
\hline Catechin & 1.91 & 289 & 203,109 & $10.2 \pm 0.2$ & $5.6 \pm 0.9$ & $1.6 \pm 0.2$ & $3.3 \pm 0.5$ \\
\hline Gallocatechin gallate & 2.26 & 457 & $305,169,125$ & $32.7 \pm 0.7$ & $18.1 \pm 2.4$ & $14.3 \pm 0.8$ & $25.3 \pm 0.6$ \\
\hline Epicatechin & 2.42 & 289 & 162,125 & $23.5 \pm 0.4$ & $14.2 \pm 1.4$ & $1.3 \pm 0.3$ & $1.7 \pm 0.1$ \\
\hline Epigallocatechin gallate & 2.46 & 457 & $305,169,125$ & N.D. & N.D. & $1.92 \pm 0.03$ & $2.7 \pm 0.1$ \\
\hline Epicatechin gallate & 2.80 & 441 & 289,169 & $10.5 \pm 0.7$ & $6.6 \pm 0.7$ & $4.22 \pm 0.08$ & $8.4 \pm 0.8$ \\
\hline \multicolumn{4}{|c|}{ Total content of analyzed flavan-3-ols } & $(85.6 \pm 1.3)^{\mathrm{a}}$ & $(50.9 \pm 5.4)^{\mathrm{b}}$ & $(27.5 \pm 1.3)^{c}$ & $(49.7 \pm 1.7)^{\mathrm{d}}$ \\
\hline Rutin & 3.45 & 609 & 301,271 & $13.7 \pm 1.5$ & $7.4 \pm 0.1$ & N.D. & N.D. \\
\hline Kaempferol & 4.48 & 285 & 187 & $0.3 \pm 0.0$ & $0.3 \pm 0.00$ & N.D. & N.D. \\
\hline Quercetin & 4.62 & 301 & 179,151 & $10.9 \pm 0.5$ & $7.5 \pm 0.02$ & $1.8 \pm 0.2$ & $3.6 \pm 0.4$ \\
\hline \multicolumn{4}{|c|}{ Total content of analyzed flavonols } & $(25.0 \pm 1.0)^{\mathrm{a}}$ & $(15.3 \pm 1.0)^{\mathrm{b}}$ & $(1.8 \pm 0.2)^{\mathrm{c}}$ & $(3.6 \pm 0.3)^{c}$ \\
\hline \multicolumn{4}{|c|}{ Total content of analyzed flavonoids } & $(110.6 \pm 2.4)^{\mathrm{a}}$ & $(66.2 \pm 4.4)^{\mathrm{b}}$ & $(29.3 \pm 1.6)^{c}$ & $(53.4 \pm 1.3)^{\mathrm{d}}$ \\
\hline
\end{tabular}

Values are expressed as means \pm standard error $(N=2)$. Values in a row followed by different letters for each infusion and fermented beverage are significantly different $(\mathrm{p}<0.05)$ by Tukey's test. $t_{\mathrm{R}}=$ retention time, N.D. $=$ not detected

Table 3. Chain-breaking activity, radical scavenging (DPPH assay), inhibition of human serum lipid oxidation (TBARS), nitric oxide (NO) scavenging assay, and inhibition of angiotensin-converting enzyme (ACE) of infusions and fermented beverages with kombucha consortium

\begin{tabular}{|c|c|c|c|c|c|}
\hline & \multirow{2}{*}{$\frac{\text { Chain-breaking activity }}{-1 /(\mathrm{min} / \mathrm{mg})}$} & \multicolumn{4}{|c|}{$\mathrm{IC}_{50} /(\mu \mathrm{g} / \mu \mathrm{L})$} \\
\hline & & $\mathrm{DPPH}$ & TBARS & $\mathrm{NO}$ & ACE inhibition \\
\hline \multicolumn{6}{|l|}{ Litsea glaucescens } \\
\hline Infusion & $(5.1 \pm 0.4)^{\mathrm{a}}$ & $(4.6 \pm 0.1)^{\mathrm{a}}$ & $(1.9 \pm 0.1)^{\mathrm{a}}$ & $(22.4 \pm 6.3)^{\mathrm{a}}$ & $(0.70 \pm 0.02)^{\mathrm{c}}$ \\
\hline Fermented beverage & $(5.2 \pm 0.1)^{\mathrm{a}}$ & $(2.70 \pm 0.01)^{b}$ & $(1.1 \pm 0.1)^{\mathrm{a}}$ & $(11.4 \pm 1.3)^{b}$ & $(1.08 \pm 0.01)^{\mathrm{b}}$ \\
\hline \multicolumn{6}{|c|}{ Eucalyptus camaldulensis } \\
\hline Infusion & $(3.7 \pm 0.2)^{\mathrm{b}}$ & $(3.40 \pm 0.05)^{\mathrm{c}}$ & $(0.36 \pm 0.01)^{\mathrm{b}}$ & $(6.7 \pm 0.9)^{c}$ & $(1.40 \pm 0.05)^{\mathrm{b}}$ \\
\hline Fermented beverage & $(3.0 \pm 0.1)^{\mathrm{b}}$ & $(2.7 \pm 0.1)^{\mathrm{b}}$ & $(1.0 \pm 0.3)^{\mathrm{a}}$ & $(5.8 \pm 0.8)^{c}$ & $(2.61 \pm 0.01)^{\mathrm{a}}$ \\
\hline Catechin & $(1.0 \pm 0.1)^{\mathrm{c}}$ & $(3.8 \pm 0.1)^{c}$ & $(1.0 \pm 0.2)^{\mathrm{a}}$ & $(2.5 \pm 0.3)^{\mathrm{d}}$ & - \\
\hline Captopril & N.D. & N.D. & N.D. & N.D. & $(2.8 \pm 0.2)^{\mathrm{a}}$ \\
\hline
\end{tabular}

Values are means of duplicate determinations \pm standard error. Different letters in each column indicate statistical difference ( $\mathrm{p} \leq 0.05)$ by Tukey's test. N.D.=not determined

DPPH radical (1.2- to 1.7-fold than unfermented infusions). In concordance with our results, Jayabalan et al. (24) reported an enhancement in DPPH scavenging activity in fermented beverages with respect to unfermented tea. Previous studies with kombucha beverages attributed the antioxidant activity to the polyphenols and catechins, with a statistically significant correlation between the phenolic content and the DPPH scavenging capacity $(\mathrm{R}=0.7180 ; 24)$. However, in our work a lower correlation by Spearman`s test $(\mathrm{p}<0.05)$ was observed $(R=0.3162)$. This could be explained by the existence of a partial oxidation of polyphenols, forming macromolecular compounds, and therefore decreasing their relative concentration. However, these compounds could still provide a noteworthy radical scavenging activity as we demonstrated in this work.
In order to complement the analysis of antioxidant activity of plant infusions and fermented beverages, we evaluated the inhibition of lipid peroxidation in pre-oxidized healthy human serum. Results showed that both herbal infusions have antioxidant capacity with $\mathrm{IC}_{50}$ values close to the positive control (catechin). Improvement of antioxidant capacity of fermented beverages was not observed, showing similar $\mathrm{IC}_{50}$ values to the unfermented infusions. Jayabalan et al. (18) reported that the antioxidant activity is extremely dependent on the used conditions and the analyzed substrates or products; therefore, not all methods give the same response.

Authors such as Arnao (26) reviewed limitations of antioxidant activity assays, suggesting that the activity must be measured using more than one method, includ- 
ing primary and secondary oxidation products, and using tests that measure specific substrates or products. Therefore, we used a third method: the nitric oxide (NO) scavenging assay. Nitric oxide reacts with superoxide $\left(\mathrm{O}_{2}^{-{ }^{-}}\right)$to form the peroxynitrite anion, which is a potentially strong oxidant as the decomposition of this molecule produces hydroxyl radical and nitrogen dioxide, contributing significantly to oxidative cell damage (21). The results of the $\mathrm{NO}$ assay showed that infusions had weaker effect on $\mathrm{NO}$ scavenging activity than catechin, used as a positive control (Table 3). However, the antioxidant activity increased with the fermentation ( $49 \%$ of L. glaucescens and $14 \%$ of E. camaldulensis), unlike the DPPH test results, where we did not find any statistically significant correlation between the phenolic content and antioxidant activity. A high correlation $(\mathrm{R}=0.8000)$ between polyphenol content and NO scavenging response by Spearman's test $(\mathrm{p}<0.05)$ was observed. The same was observed by Jayabalan et al. (24), reporting that during fermentation, polyphenol structural modifications occurred, such as glycosylation, resulting in better scavenging performance on nitrogen radicals.

\section{Antihypertensive activity in vitro}

Finally, the antihypertensive potential of fermented beverages was evaluated in vitro through the inhibition of the angiotensin-converting enzyme (ACE) activity. ACE is a carboxypeptidase, and it participates in regulating blood pressure by converting an inactive form of the decapeptide angiotensin I to a potent vasopressor octapeptide, angiotensin II. Therapeutic ACE inhibitors represent an important and common class of pharmaceuticals for hypertension control (27). Results of ACE inhibition activity demonstrate that herbal infusions inhibit the activity of this enzyme (Table 3). L. glaucescens infusion had the highest effect, being similar to the positive control (captopril, main pharmaceutical used to control blood pressure). On the other hand, fermented beverages did not enhance the ACE inhibitory potential of herbal infusions; on the contrary, fermentation process reduced the positive effect of infusions (1.8-fold of E. camaldulensis and 15.1-fold of L. glaucescens). However, the $\mathrm{IC}_{50}$ of fermented beverages was still lower than of the positive control. Hur et al. (28) proposed that the increase or decrease of bioactivity of phenolic compounds produced by fermentation may be influenced by various factors, including microorganism species, $\mathrm{pH}$, temperature, solvent, water content, fermentation time, kind of plant material and aerobic conditions. Thus, the variations of results could be attributed to these factors and not only to the final conversion of bioactive compounds.

\section{Conclusions}

The present study has demonstrated that fermentation of Litsea glaucescens and Eucalyptus camaldulensis infusions with kombucha consortium modifies their concentration of phenolic compounds, and their antioxidant and antihypertensive activities. Fermented beverages exhibited increased free radical scavenging activities, but this response depends on the used medium, substrate and mainly on the plant material used for infusion prepara- tion. Additionally, it is interesting to note that E. camaldulensis and L. glaucescens can be considered as natural sources of biocompounds with antihypertensive potential (especially the latter) either as infusions or fermented beverages. Therefore, they can be considered for further investigations, especially for in vivo assays.

\section{Acknowledgements}

This project was supported by 'Redes Temáticas de Colaboración Académica: Nanotecnología y Omics para el estudio de Nutracéuticos' (SEP-PRODEP). We acknowledge the Area of Ecology and Systemics from CIIDIR-IPN, Unidad Durango for their support. Also we appreciate the technical support of Ignacio Velázquez-Jiménez. The authors gratefully acknowledge Bogar Vallejo and Tradu-c services for language revision.

\section{References}

1. Astill C, Birch MR, Dacombe C, Humphrey PG, Martin PT. Factors affecting the caffeine and polyphenol contents of black and green tea infusions. J Agric Food Chem. 2001;49: 5340-7. http://dx.doi.org/10.1021/jf010759+

2. Annuzzi G, Bozzetto L, Costabile G, Giacco R, Mangione A, Anniballi $G$, et al. Diets naturally rich in polyphenols improve fasting and postprandial dyslipidemia and reduce oxidative stress: a randomized controlled trial. Am J Clin Nutr. 2014;99:463-71.

http://dx.doi.org/10.3945/ajcn.113.073445

3. Nileeka Balasuriya B, Vasantha Rupasinghe H. Plant flavonoids as angiotensin converting enzyme inhibitors in regulation of hypertension. Funct Food Health Dis. 2011;5:172-88.

4. Aloulou A, Hamden K, Elloumi D, Ali MB, Hargafi K, Jaouadi $B$, et al. Hypoglycemic and antilipidemic properties of kombucha tea in alloxan-induced diabetic rats. BMC Complement Altern Med. 2012;12:63. http://dx.doi.org/10.1186/1472-6882-12-63

5. Velićanski AS, Cvetković DD, Markov SL, Tumbas Šaponjac VT, Vulić JJ. Antioxidant and antibacterial activity of the beverage obtained by fermentation of sweetened lemon balm (Melissa officinalis L.) tea with symbiotic consortium of bacteria and yeasts. Food Technol Biotechnol. 2014;52:420-9. http://dx.doi.org/10.17113/ftb.52.04.14.3611

6. Vijayaraghavan R, Singh M, Rao PVL, Bhattacharya R, Kumar P, Sugendran K, et al. Subacute (90 days) oral toxicity studies of kombucha tea. Biomed Environ Sci. 2000;13:293-9.

7. Vázquez-Cabral BD, Rocha-Guzmán NE, Gallegos-Infante JA, González-Herrera SM, González-Laredo RF, Moreno-Jiménez MR, Córdova-Moreno ITS. Chemical and sensory evaluation of a functional beverage obtained from infusions of oak leaves (Quercus resinosa) inoculated with the kombucha consortium under different processing conditions. Nutrafoods. 2014;13:169-78.

http://dx.doi.org/10.1007/s13749-014-0035-0

8. Herrera-Carrera E, Moreno-Jiménez MR, Rocha-Guzmán NE, Gallegos-Infante JA, Díaz-Rivas JO, Gamboa-Gómez CI, González-Laredo RF. Phenolic composition of selected herbal infusions and their anti-inflammatory effect on a colonic model in vitro in HT-29 cells. Cogent Food Agric. 2015;1: 1059033. http://dx.doi.org/10.1080/23311932.2015.1059033

9. Singab AN, Ayoub N, Al-Sayed E, Martiskainen O, Sinkkonen J, Pihlaja K. Phenolic constituents of Eucalyptus camaldulensis Dehnh, with potential antioxidant and cytotoxic activities. Rec Nat Prod. 2011;5:271-80. 